\title{
Expectations for 1995
}

It is indeed an honor to serve as the 20th president of the Materials Research Society. The hundreds of volunteers who have contributed their talents and time to the Society since its founding 22 years ago have created a vibrant organization whose scope far exceeds anything the founders originally envisioned. There is much to be proud of. And yet MRS can little afford to rest on its past successes. These are interesting times for materials research in all sectors, both in the United States and beyond, presenting both challenges and opportunities for the Society. The MRS tradition of innovation will be even more critical than in the past if we are to meet the evolving needs of our members.

Technical meetings are at the heart of the Society's existence. They are the reason that many people first discover MRS and the magnet that entices them to continue their affiliation. It is critical that our meetings continue to fulfill the needs of the membership. Last year a meeting quality task force considered ways to monitor and improve the meetings. This year our job will be to implement their recommendations so that our meetings remain relevant to the constituencies they are intended to serve.

The MRS membership is remarkably diverse. While the Society has always had strong representation from academia, industry, and government, other recent trends are noteworthy. For example, more than half of our members now join MRS by means other than attending meetings. Student members, arguably the future of the Society, make up $20 \%$. And nearly $30 \%$ of all MRS members are from outside the United States. Each of these membership segments brings it own

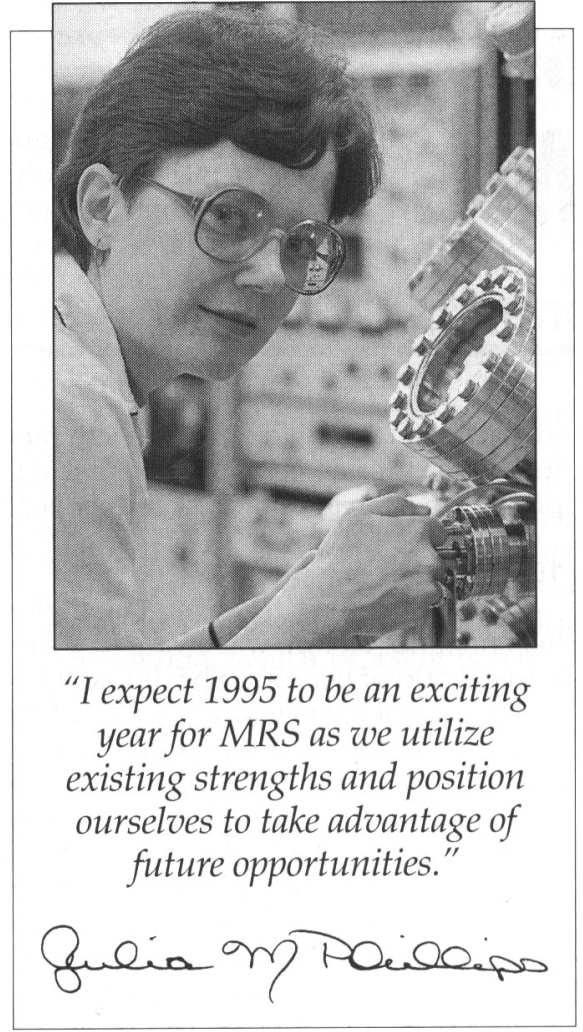

valuable perspective to the Society, but each group also has its own set of needs and expectations. It is imperative that we both understand the needs and take advantage of the talents of this diverse membership.

MRS is not the only professional society concerned with materials science and engineering. In fact, most MRS members are also affiliated with other organizations. In this "age of limits," we should explore and strengthen our interactions with other professional societies. This year several other professional materials-based societies are represented on our External Affairs Committee, the body responsible for intersociety interactions on the technical level. It is our hope that this will be the first step toward better coordination of technical programming and less competition among meetings of different societies. On another level, advances in materials have contributed much to the quality of life we enjoy, and will continue to be important for the foreseeable future. Since 1990, MRS has been seeking to convey this message to policymakers in Washington. This message could have more clout if it were the joint statement of a collection of materials societies representing many tens of thousands, if not hundreds of thousands of members, rather than of a single organization. It is important to explore ways in which MRS can work with other materials-focused societies to educate policymakers about the importance of materials research.

I expect 1995 to be an exciting year for MRS as we utilize existing strengths and position ourselves to take advantage of future opportunities. The Society will, however, continue to be a vital organization only so long as it attracts and engages high quality volunteers and responds to the needs of its members. Let the Society leadership hear from you!

JuLia M. PhILLIPS

Julia M. Phillips

Thin Film Research Group

Room 1D-151

600 Mountain Avenue

Murray Hill, NJ 07974

Fax: (908) 582-2521

E-mail: jmp@allwise.att.com

\section{Attending the MRS Spring Meeting? CURRENT MRS MEMBERS PAY A LOWER REGISTRATION FEE.}

\author{
All MRS Fall and Spring Meeting registrations now include a complimentary \\ membership benefit. And as long as you keep your membership current, \\ you'll always pay a lower registration fee.
}

Questions? Contact MRS Member Services, 412/367-3004 x402; fax 412/367-4373; e-mail INFO@MRS.ORG. 